Rev Invest Clin. 2019;71:381-6

\title{
ASSOCIATION OF VITAMIN D WITH MILD COGNITIVE IMPAIRMENT AND ALZHEIMER'S DEMENTIA IN OLDER MEXICAN ADULTS
}

\author{
Sara G. Aguilar-Navarro ${ }^{1,2}$, Alberto J. Mimenza-Alvarado ${ }^{1,2}$, Gilberto A. Jiménez-Castillo ${ }^{1}$ \\ Leonardo A. Bracho-Vela ${ }^{1}$, Sara G. Yeverino-Castro ${ }^{1}$, and José A. Ávila-Funes ${ }^{2,3}$
}

${ }^{1}$ Geriatric Medicine and Neurology Fellowship Program, and ${ }^{2}$ Department of Geriatrics, Instituto Nacional de Cièncias Médicas y Nutrición Salvador Zubirán, Mexico City, Mexico; ${ }^{3}$ University of Bordeaux, Inserm, Bordeaux Population Health Research Center, Bordeaux, France

\section{ABSTRACT}

Background: It has been proposed that Vitamin $D$ helps reduce the accumulation of cerebral $\beta$-amyloid-42 by innate immune stimulation and phagocytosis activation. An association between low Vitamin D levels and Alzheimer's dementia (AD) häs been established. We determined the association between Vitamin D, mild cognitive impairment (MCI), and AD in older Mexican adults (> 65 years). Methods: Cross-sectional study conducted at the memory clinic in a tertiary-level hospital in Mexico Gity. We evaluated subjects with $\mathrm{MCl}, \mathrm{AD}$, and normal cognition (NC) with available serum Vitamin D [25(OH)D] levels (past 6 months). Three categories were assigned according to $25(\mathrm{OH}) \mathrm{D}$ levels: sufficiency (> $30 \mathrm{ng} / \mathrm{mL}$ ), insufficiency $(21-29 \mathrm{ng} / \mathrm{mL})$, ā̄ $\mathrm{h} d \mathrm{defi}-$ ciency ( $\leq 20 \mathrm{ng} / \mathrm{mL}$ ). Descriptive statistics, means and standard deviations were used. Logistic regression analyses adjusted by age, sex, and educational level were performed. Results: We evaluated 208 patients. Mean age was $79 \pm 1$ year, 65\% (n= 136 ) were female; and mean educational level was $6.7 \pm 2.3$ years. Thirty-one subjects $(14 \%)$ had NC; $42 \%(n=88)$ had $\mathrm{MCl}$; and $43 \%(n=89)$ had AD. Prevalence of Vitamin D deficiency was $54 \%$, more frequent in the AD group (64\%) followed by the $\mathrm{MCl}$ $(59 \%)$ and $\mathrm{NC}(13 \%)(\mathrm{p}<0.001)$ groups. In the multivariate logistic regression analysis, Vitamin D deficiency was associated with $\mathrm{MCl}$ (HR 25.02 [confidence interval 95\% 4.48-139]; $\mathrm{p}<0.001$ ) and AD (HR 41.7 [5.76-301]; $p<0.001$ ) after adjusting for confounders. Conclusions: Serum Vitamin D deficiency was associated with $\mathrm{MCl}$ and dementia; low levels produced $\underline{\underline{a}}$ greater effect over executive functions. (REV INVEST CLIN. 2019;71:381-6)

Key words: Vitamin D. Mild cognitive impairment. Dementia. Older adult.

*Corresponding author:

Alberto José Mimenza-Alvarado

E-mail: a.mimenza@hotmail.com
Received for publication: 2-05-2019

Approved for publication: 13-06-2019

DOI: $10.24875 / R I C .19003079$ 


\section{INTRODUCTION}

Brain regulation of Vitamin $D$ is possible by neuronal cytochromes (CYP27B1 and CYP24A1) involved in the conversion of $25 \mathrm{OHD} 3$ to $1,25-\mathrm{OH}_{2} \mathrm{D}_{3}$, and $1,25-\mathrm{OH} 2 \mathrm{D} 3$ to $24,25-\mathrm{OH} 2 \mathrm{D}_{3}{ }^{1}$. Vitamin $\mathrm{D}$ receptors are located in diverse brain areas: cerebellum, thalamus, hypothalamus, basal forebrain, hippocampus, olfactory system, cingulate gyrus, and temporal, and orbital cortex ${ }^{2}$. It has been proposed that Vitamin D helps to reduce the accumulation of cerebral $\beta$-amyloid-42 by innate immune stimulation and phagocytosis activation. Vitamin D also regulates neurotrophic factors and has antioxidant properties ${ }^{3}$. Its deficiency is common in the older adult. In the United States, the National Health and Nutrition Examination Survey found a combined Vitamin D deficiency and insufficiency $(<30 \mathrm{ng} / \mathrm{mL})$ of $42 \%$ in the general population ${ }^{4}$, and, in Mexico, the reported prevalence is $37 \%$. However, other studies have shown a 70-90\% deficiency in older adults with cognitive impairment ${ }^{5}$. An association has been previously established between low levels of Vitamin D and Alzheimer's dementia (AD) and all-type dementia ${ }^{6-8}$. Different studies show that Vitamin $D$ deficiency is associated with other health problems, such as lower general health status. As such, Vitamin D deficiency increases susceptibility and accelerates the disease, rather than being a direct cause of dementia9. Nevertheless, studies have also shown a directly proportional relationship between serum $\mathrm{Vi}$ tamin D levels and cognitive performance, particularly concerning executive function ${ }^{10}$. In Mexico, a community study of older adults did not find an association between cognitive performance and Vitamin $D$ levels ${ }^{11,12}$. Therefore, this study aimed to determine the association of serum Vitamin $D$ levels with mild cognitive impairment $(\mathrm{MCl})$ and $A D$ in older Mexican adults.

\section{METHODS}

\section{Study population}

This cross-sectional study was conducted at the memory clinic of a tertiary-level university hospital in Mexico City. Each subject completed clinical and neuropsychological evaluations between January 2018 and January 2019. Subjects who were 65 years or older with available serum Vitamin D levels (in the past 6 months) were included and assigned to 0 he of three groups: $\mathrm{MCl}$, probable $\mathrm{AD}$, and normal cognition (NC). For this study, we excluded subjects with a diagnosis of: major depressive disorder without treatment, non-AD dementias, other neurologicatedisorders including structural cerebral lesions whic could affect cognitive functions (i.e., acute stroke $\bar{e}_{3}$ brain tumor or normal-pressure hydrocephalus). We also included subjects with malabsorption symdrome (Crohn's or celiac disease), chronic kidney disease, osteoporosis, sarcoidosis, tuberculosis, histopłasmosis or an active granulomatous disease. Subjects who were currently receiving Vitamin D supplements or other medications (bisphosphonates, anticonvừlsants, antimycotics) for any cause were also excluded. Sociodemographic variables and health status included information about the subject's sex, age, years of education, and presence or absence of diabetes, dyslipidemia, hypertension, hypothyroidism, atrial fibrillation, and polypharmacy ${ }^{13}$. The local Ethics Committee approved the study (GER-2738-18-19-1).

\section{Neuropsychological evaluation}

Subjects assigned to the $\mathrm{MCl}$ group met the following criteria: Petersen $\mathrm{MCl}$ proposed criteria ${ }^{14}$ and the Statistical Manual of Mental Disorders-Fifth Edition (DSM-5) criteria for minor neurocognitive disorder ${ }^{15}$; clinical dementia rating (CDR) scale ${ }^{16}$ score of 0.5 points; a mini-mental state examination (MM̂MSE) ${ }^{17}$ score of 24-27; and preserved functional capacity measured by Katz Index (Basic Activities of Dailly Living) ${ }^{18}$ and Lawton-Brody (Instrumental Activities of Daily Living) scale ${ }^{19}$. The diagnosis of probable $A D$ was made according to the National Institute of Aging and the Alzheimer's Association (NIA-AA-2013) and DSM-5 Criteria ${ }^{15,20}$. A CDR $\geq 1$ and an MMSE score < 24 were also considered for diagnosis. The cognitive evaluation included the following tests: verbal fluency test $^{21}$ (considered abnormal if the subjects did not produce a certain number of words according to their educational level); the Frontal Assessment Battery (FAB) (score < 11 was considered as executive dysfunction $)^{22,23}$; and the clock-drawing test ${ }^{24}$ (1 point was assigned for each mistake; greater executive dysfunction was considered with higher scores). The NC group included subjects without a memory complaint and with NC tests results, adjusted for age and educational level. 
Table 1. Participants' cognitive performance according to serum Vitamin D levels

\begin{tabular}{|c|c|c|c|c|}
\hline Cognitive status & $\begin{array}{l}\text { Sufficiency } \\
(n=13)\end{array}$ & $\begin{array}{l}\text { Insufficiency } \\
\quad(n=83)\end{array}$ & $\begin{array}{l}\text { Deficiency } \\
(n=112)\end{array}$ & p value \\
\hline MMSE, mean (SD) & $27(3)$ & $25(4.7)$ & $22.7(5.5)$ & $<0.009$ \\
\hline MMSE domains & & & & $\frac{\check{L}}{4}$ \\
\hline z-scores (SD) & & & & $\underline{\underline{\underline{n}}}$ \\
\hline Orientation & $0.58(0.59)$ & $0.15(0.85)$ & $-0.17(1.09)$ & $<0.009$ \\
\hline Attention & $0.37(0.88)$ & $0.15(0.99)$ & $-0.15(0.99)$ & $<0.00 \overline{1}$ \\
\hline Memory (Coding) & $0.42(1.05)$ & $0.12(0.59)$ & $-0.14(1.19)$ & 0.10 \\
\hline Memory (Evocation) & $0.75(0.75)$ & $0.10(1.05)$ & $-0.16(0.93)$ & $<0.001$ \\
\hline Executive function. mean (SD) & & & & $\frac{c}{0}$ \\
\hline Clock-drawing test & $1.69(2.01)$ & $2.78(2.87)$ & $3.36(2.81)$ & $0.02 \stackrel{\aleph}{=}$ \\
\hline $\mathrm{FAB}$ & $13.38(5.5)$ & $11.96(3.82)$ & $10.18(3.28)$ & $<0.001$ \\
\hline Verbal fluency & $12.08(4.05)$ & $9.14(4.8)$ & $6.99(4.46)$ & $<0.001$ \\
\hline
\end{tabular}

Serum Vitamin D levels: sufficiency: > $30 \mathrm{ng} / \mathrm{mL}$, Insufficiency: $21-29 \mathrm{ng} / \mathrm{mL}$, Deficiency: $\leq 20 \mathrm{ng} / \mathrm{mL}$. MMSE: mini-mental state examination, FAB: Frontal assessment battery. Means and SD presented. z-scores shown on MMSE domains.

*Kruskal-Wallis.

SD: standard deviations.

\section{Serum Vitamin D determination}

Serum 25-hidroxyvitamin D [25(OH)D] levels were measured by the ARCHITECT i2000 SR system 5 P02 (Abbott). A chemiluminescent microparticle immunoassay was used ${ }^{25}$. This assay showed precision with a coefficient of variance (CV\%) $<5 \%$. For low, average, and high Vitamin D levels, precision remained accurate. At an average of $25 \mathrm{OH}-\mathrm{D}$ of $5.3 \mathrm{ng} / \mathrm{mL}, 20.6$ $\mathrm{ng} / \mathrm{mL}$, and $72.2 \mathrm{ng} / \mathrm{mL}$, the intra-assay $\mathrm{CVs}$ were $3.9 \%, 2.1 \%$, and $2.3 \%$, respectively. The corresponding inter-assay CVs were $1.6 \%, 1.3 \%$, and $1.2 \%$. The following categories for this analysis were assigned: $>30 \mathrm{ng} / \mathrm{mL}$, sufficiency; $21-29 \mathrm{ng} / \mathrm{mL}$, insufficiency; and $<20 \mathrm{ng} / \mathrm{mL}$, deficiency ${ }^{12,26}$.

\section{Statistical analysis}

When appropriate, arithmetic means, standard deviations and frequencies or proportions were used to describe variables. Chi-square test was used to compare qualitative data and ANOVA for continuous variables. The cognitive domains evaluated through MMSE were compared after their transformation to $z$-scores. To determine the strength of association between Vitamin $D$ levels and the subjects' cognitive status ( $\mathrm{MCl}$ or probable $A D$ ), univariate and multivariate logistic regression models adjusted for age, sex, and education level were performed. $p<0.05$ value was considered significant. Statistical analysis was performed using SPSS software for Windows (SPSS Inc., Chicago. IL, version 22).

\section{RESULTS}

A total of 208 subjects were included. Mean age was $79 \pm 1$ year; $65 \%(n=136)$ were female, and mean educational level was $6.7 \pm 2.3$ years. Eighty-nine subjects (43\%) had $\mathrm{AD} ; 88(42 \%)$ had $\mathrm{MCl}$; and 31 (14\%) had NC. Sociodemographic variables and health status are shown in Supplementary Table S1; $75 \%(n=157)$ had polypharmacy, 61\% ( $n \stackrel{\oplus}{E} 128)$ had hypertension diagnosis, $39 \%(n=81)$ had dyslipidemia, $36 \%(n=74)$ had diabetes, $16 \%(n=55)$ had hypothyroidism, and $7 \%(n=14)$ had atrial fibrillation. The overall prevalence of severe Vitamin deficiency was $54 \%$, being more frequent in the $A D$ group (64\%), followed by the $\mathrm{MCl}(59 \%)$ and the NC(13\%) $(\mathrm{p}<0.001)$ groups. Compared to the NC and the MCl groups, subjects in the AD group were older $(81$ vs. 73 and 79 years, respectively; $p<0.001$ ), hăd less years of education (5.7 vs. 9.9 and 6.3 years, tively; $p<0.001$ ), and had lower Vitamin D levels (18.2 vs. 26 and $19.2 \mathrm{ng} / \mathrm{mL}$, respectively; $p<\bar{\theta} .001$ ). Cognitive performance scores, according to Vitamin $D$ levels, are shown in Table 1. Subjects with Severe deficiency of Vitamin D had a lower MMSE score when compared with the groups of sufficiency and 
Table 2. Univariate and multivariate regression analyses

\begin{tabular}{|c|c|c|c|c|}
\hline $\mathrm{MCl}$ & $\begin{array}{c}\text { Model } 1 \\
\text { HR }(95 \% \mathrm{Cl})\end{array}$ & $\mathrm{p}$ value & $\begin{array}{c}\text { Model } 2 \mathrm{HR} \\
(95 \% \mathrm{Cl})\end{array}$ & p value \\
\hline Vitamin D & & & & (C) \\
\hline Sufficiency & 1 & & 1 & 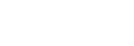 \\
\hline Insufficiency & $2.88(0.750-11.11)$ & 0.05 & $4.15(0.95-18.14)$ & $0.05 \frac{\mathrm{s}}{n}$ \\
\hline Deficiency & $22.75(4.61-112)$ & $<0.001$ & $25.02(4.48-139)$ & $<0.001=$ \\
\hline Dementia & & & & $\vec{\alpha}$ \\
\hline Vitamin D & & & & + \\
\hline Sufficiency & 1 & & 1 & 4 \\
\hline Insufficiency & $5.25(0.988-27.89)$ & 0.05 & $6.07(1.01-36.20)$ & 0.04 \\
\hline Deficiency & $49(7.54-318)$ & $<0.001$ & $41.7(5.76-301)$ & $<0.001 \bar{v}$ \\
\hline
\end{tabular}

Model 1: univariate analysis, Model 2: multivariate analysis, both adjusted for age, sex and years of education. Vitamin D sufficiency $>30 \mathrm{ng} / \mathrm{mL}$, Insufficiency: 21-29 ng/mL, Deficiency: $\leq 20 \mathrm{ng} / \mathrm{mL}$.

insufficiency $(22.7 \pm 5.5$ vs. $27 \pm 3$ and $25 \pm 4.7$ points, respectively; $p<0.001$ ). The Vitamin D deficiency group also had worse performance in all MMSE domains measured: orientation, attention, and evocation. Executive function was measured by the $F A B$, and statistically significant differences were observed when comparing the deficiency group with the sufficiency of Vitamin D group (10.1 \pm 3.2 vs. $13.3 \pm 5.5$; $p<0.01$ ). The same differences were noted between these groups in the clock-drawing test scores (3.36 \pm 2.8 vs. $1.69 \pm 2$ points; $p=0.002$ ), phonemic verbal fluency number of words produced $(6.9 \pm 4.4$ vs. 12 \pm 4 words, respectively; $p<0.001$ ), and semantic verbal fluency (11.2 vs. 12.5 words; $p=0.20$ ).

In the univariate logistic regression analysis, the Vitamin $D$ deficiency and insufficiency groups were significantly associated with $\mathrm{MCl}$ (HR: 22.7, 95\% confidence interval $[\mathrm{Cl}]$ 4.6-112; $\mathrm{p}<0.001$, and $\mathrm{HR} 2.88$, $95 \% \mathrm{Cl} 0.75-11.11 ; \mathrm{p}<0.001$, respectively). In the group with dementia diagnosis, when compared with the sufficiency of Vitamin D control group, significant associations were also observed for the deficiency and insufficiency states (HR: $49,95 \% \mathrm{Cl} 7.5-318 ; \mathrm{p}$ $<0.01$ and HR: $5.2,95 \% \mathrm{Cl} 0.9-27.8 ; p=0.05$, respectively). After adjusting for age, sex, and years of education, the association remained significant in the $\mathrm{MCl}$ group in both the deficiency (HR: $25,95 \% \mathrm{Cl}$ 4.4-139; $\mathrm{p}<0.001$ ) and insufficiency states (HR: 4.1, $95 \% \mathrm{Cl} 0.9-18.1 ; \mathrm{p}<0.01$ ). In the AD group, the association also remained significant in both the deficiency (HR: 41.7, 95\% Cl 5.7-301; $p<0.001$ ) and insufficiency (HR: 6, 95\% Cl 1.0-36.2; $=0.04$ ) states (Table 2).

\section{DISCUSSION}

Our study showed that Vitamin D deficiency was independently associated with $\mathrm{MCl}$ and $\mathrm{AD}$. Previous studies have established an association betwè $\mathrm{E}$ itamin D deficiency, all-type dementia, and $\overline{A D}{ }^{27}$. A meta-analysis that included 20,750 participants from different countries found a significant association between Vitamin D status and cognitive impairment (HR $1.24,95 \% \mathrm{Cl} 1.14-1.35 ; \mathrm{p}<0.001)^{9}$. A cohort study which included 1200 older Chinese adults and had a 2-year follow-up, observed an association between low Vitamin $\mathrm{D}$ levels and worsened global cognitive function (HR: $2.89,95 \% \mathrm{Cl} 1.36-6.14 ; \mathrm{p}=0.004)^{28}$. In another multi-ethnic older adult longitudinabstudy, with a 4.8-year follow-up, cognitive impairment was more frequent in those subjects with Vitamin $\Phi$ deficiency. The study with the longest follow-up was the Cardiovascular Health Study in the United States. This study included 658 cognitively healthy partiegpants and the authors found a higher risk of all-type dementia (HR: $2.25,95 \% \mathrm{Cl} 1.2-4.1, \mathrm{p}=0.002)$ and $\overline{\mathrm{AD}}$ (HR: $2.2,95 \% \mathrm{Cl} 1-4.8, \mathrm{p}=0.008$ ) associated with Vitamin D deficiency ${ }^{5}$.

The pathophysiological mechanisms that link low Vitamin D levels with a greater dementia risk have been explained through the Vitamin D-receptor hypothesis, 
in which the location of these receptors in many different areas of the brain, including memory areas such as the hippocampus and dental gyrus, is proposed as a possible contributing factor to cognitive impairment $^{2}$. The $1 \alpha$-hydroxylase enzyme, which is responsible for the hydroxylation of $[25(\mathrm{OH}) \mathrm{D}]$ to its active form 1,25 dihydroxyVitamin D3 (1,25-D3), contributes to the homeostasis in calcium signaling, neurotrophic factors, and synaptic plasticity ${ }^{29}$. In vitro, Vitamin D stimulates macrophages, which, in turn, increase $\beta$-amyloid plaque clearance ${ }^{3}$.

Regarding cognitive domains, our study demonstrated that subjects with Vitamin D deficiency had worse performance in attention, evocation, orientation, and mainly executive function domains. A meta-analysis established a strong association between executive dysfunction, memory, and Vitamin D deficiency ${ }^{30,31}$. This could be explained by the integrity of frontalsubcortical circuits, in which an injury, including vascular lesions, could produce executive dysfunction. For this reason, low serum levels of Vitamin D could explain the loss of its neuroprotective effects ${ }^{32}$. In preclinical stages or $\mathrm{MCl}$, only a French study has evaluated Vitamin $D$ deficiency; a positive association between low Vitamin $\mathrm{D}$ levels and any type of $\mathrm{MCl}$ was demonstrated (HR 25.4, 95\% Cl 3.2-201.2, $\mathrm{p}=$ $0.002)^{7}$. This evidence supports the notion that cognitive impairment progression could be modified in the early stages of the disease. The effect of Vitamin $\mathrm{D}$ in $\mathrm{MCl}$ is caused through the same mechanisms as in dementia since it acts as a neurosteroid (i.e., crosses the blood-brain barrier and binds to its receptor in neurons). It is possible that hypovitaminosis $D$ decreases defense mechanisms, participating in brain dysfunction and cognitive decline. Therefore, it seems reasonable to consider that low levels of Vitamin $D$ in the early or preclinical stages $(\mathrm{MCl})$ participate in the progression of cognitive disorders ${ }^{7,33}$.

The main limitation of this study is related to its cross-sectional nature. The relationship between $\mathrm{Vi}$ tamin $D$ deficiency and dementia determined through a single time-point of measurement may be susceptible to bias, as well as differences in age and level of education between groups. Another fact that must be taken into account is that exposure to sunlight was not measured. However, the results of this study open the possibilities for other trials, such as those with a longitudinal design. The strength of our study is that it included Mexican subjects with $\mathrm{MCl}$ and $\mathrm{A}$ diagnoses, who were selected on the same season of the year and had complete clinical and neuropsychölogical evaluations, leading to a comprehensive cognitjive domain analysis performed in subjects with Vitamin D deficiency. This could represent an opportunity to influence a potentially modifiable risk factor teto improve the course of the disease.

\section{SUPPLEMENTARY DATA}

Supplementary data are available at Revista dềlnvestigación Clínica online (www.clinicalandtranslationalinvestigation.com). These data are provided by the corresponding author and published online for the benefit of the reader. The contents of supplementary data are the sole responsibility of the authors?

\section{REFERENCES}

1. Stewart A, Wong K, Cachat J, Elegante M, Gilder T, Mohnot S, et al. Neurosteroid Vitamin D system as a nontraditional drug target in neuropsychopharmacology. Behav Pharmacö. 2010; 21:420-6.

2. Eyles DW, Smith S, Kinobe R, Hewison M, McGrath J]. Distribution of the Vitamin $D$ receptor and 1 alpha-hydroxylase in human brain. J Chem Neuroanat. 2005;29:21-30.

3. Taghizadeh M, Talaei SA, Djazayeri A, Salami M. Vitamin D supplementation restores suppressed synaptic plasticity in $\mathrm{Al}$ zheimer's disease. Nutr Neurosci. 2014;17:172-7.

4. Miller JW, Harvey DJ, Beckett LA, Green R, Farias ST, Reed BR, et al. Vitamin $D$ status and rates of cognitive dectine in a multiethnic cohort of older adults. JAMA Neurol. 2015;72: 1295-303.

5. Littlejohns TJ, Henley WE, Lang IA, Annweiler C, Beaüchet O Chaves $\mathrm{PH}$, et al. Vitamin $\mathrm{D}$ and the risk of dementia and alzheimer disease. Neurology. 2014;83:920-8.

6. Carrillo-Vega MF, García-Peña C, Gutiérrez-Robledo L $\bar{M}$, PérezZepeda MU. Vitamin D deficiency in older adults and its associated factors: a cross-sectional analysis of the mexican health and aging study. Arch Osteoporos. 2017;12:8.

7. Annweiler C, Fantino B, Schott AM, Krolak-Salmon P@Allali G, Beauchet $O$, et al. Vitamin D insufficiency and mild cognitive impairment: cross-sectional association. Eur J Neuroh. 2012; 19:1023-9

8. Olsson E, Byberg L, Karlström B, Cederholm T, Melhus H,Sjögren $P$, et al. Vitamin $D$ is not associated with incident dementia or cognitive impairment: an 18-y follow-up study in communityliving old men. Am J Clin Nutr. 2017;105:936-43.

9. Annweiler C. Vitamin D in dementia prevention. Ann NY Acad Sci. 2016;1367:57-63

10. Goodwill AM, Szoeke C. A systematic review and meta-analysis of the effect of low Vitamin D on cognition. J Am Geriatr Soc 2017;65:2161-8

11. Navarrete-Reyes AP, García-Muñoz I, García-Lara JM; TorresCarrillo NM, Amieva H, Avila-Funes JA, et al. 25-OH-Vitamin D is not associated with cognitive performance amongmexican community-dwelling older persons. J Frailty Aging. 2015,4:74-9.

12. Holick MF, Binkley NC, Bischoff-Ferrari HA, Gordon CM, Hanley DA, Heaney RP, et al. Evaluation, treatment, and prevention of Vitamin D deficiency: an endocrine society clinicalcpractice guideline. J Clin Endocrinol Metab. 2011;96:1911-30Z

13. Hajjar ER, Cafiero AC, Hanlon JT. Polypharmacy in elderly patients. Am J Geriatr Pharmacother. 2007;5:345-51. 
14. Petersen RC, Doody R, Kurz A, Mohs RC, Morris JC, Rabins PV et al. Current concepts in mild cognitive impairment. Arch Neurol. 2001;58:1985-92.

15. Sachs-Ericsson N, Blazer DG. The new DSM-5 diagnosis of mild neurocognitive disorder and its relation to research in mild cognitive impairment. Aging Ment Health. 2015;19:2-12.

16. Juva $K$, Sulkava $R$, Erkinjuntti $T$, Valvanne J, Tilvis R Clinical dementia rating (CDR)-scale in screening dementia. Neurobiol Aging. 1992;13:S2-3.

17. Folstein MF, Folstein SE, McHugh PR. Mini-mental state. A practical method for grading the cognitive state of patients for the clinician. J Psychiatr Res. 1975;12:189-98.

18. Katz S, Ford AB, Moskowitz RW, Jackson BA, Jaffe MW. Studies of illness in the aged. the index of adl: a standardized measure of biological and psychosocial function. JAMA. 1963; 185:914-9.

19. Lawton MP, Brody EM. Assessment of older people: self-maintaining and instrumental activities of daily living. Gerontologist 1969;9:179-86.

20. McKhann GM, Knopman DS, Chertkow H, Hyman BT, Jack CR Jr. Kawas $\mathrm{CH}$, et al. The diagnosis of dementia due to Alzheimer's disease: recommendations from the national institute on aging Alzheimer's association workgroups on diagnostic guidelines for Alzheimer's disease. Alzheimers Dement. 2011;7:263-9.

21. Canning SJ, Leach L, Stuss D, Ngo L, Black SE. Diagnostic utility of abbreviated fluency measures in Alzheimer disease and vascular dementia. Neurology. 2004;62:556-62.

22. Dubois B, Slachevsky A, Litvan I, Pillon B. The FAB: A Frontal assessment battery at bedside. Neurology. 2000;55:1621-6.

23. Slachevsky A, Villalpando JM, Sarazin M, Hahn-Barma V, Pillon $B$, Dubois B, et al. Frontal assessment battery and differential diagnosis of frontotemporal dementia and Alzheimer disease. Arch Neurol. 2004;61:1104-7.
24. Shulman KI. Clock-drawing: is it the ideal cognitive screening test? Int J Geriatr Psychiatry. 2000;15:548-61.

25. Hutchinson K, Healy M, Crowley V, Louw M, Rochev Y. Verification of abbott 25-OH Vitamin D assay on the architect system. Pract Lab Med. 2017;7:27-35

26. Schneider ALC, Zhao D, Lutsey PL, Gottesman RF, Sharrett AR, Rawlings AM, et al. Serum Vitamin D concentrations and cognitive change over 20 years: the atherosclerosis risk in communities neurocognitive study. Neuroepidemiology" 2018; 51:131-7.

27. Shen L, Ji HF. Vitamin D deficiency is associated with increased risk of Alzheimer's disease and dementia: evidence from metaanalysis. Nutr J. 2015;14:76.

28. Matchar DB, Chei CL, Yin ZX, Koh V, Chakraborty B, SAi-XM, et al. Vitamin $D$ levels and the risk of cognitive decline if chinese elderly people: the chinese longitudinal healthy longevity survey. J Gerontol A Biol Sci Med Sci. 2016;71:1363-8.

29. Groves NJ, McGrath JJ, Burne TH. Vitamin D as a neurosteroid affecting the developing and adult brain. Annu Rev Nutr. 2014; 34:117-41.

30. Annweiler C, Montero-Odasso M, Llewellyn DJ, Richard-Devantoy S, Duque G, Beauchet O, et al. Meta-analysis of memory and executive dysfunctions in relation to Vitamin D. J Alzheimers Dis. 2013;37:147-71.

31. Goodwill AM, Campbell S, Simpson S Jr. Bisignano M, Chiang C, Dennerstein L, et al. Vitamin D status is associated with executive function a decade later: data from the women's healthy ageing project. Maturitas. 2018;107:56-62.

32. Buell JS, Dawson-Hughes B, Scott TM, Weiner DE, Dallat GE, Qui WQ, et al. 25-hydroxyvitamin D, dementia, and cerebrovascular pathology in elders receiving home services. Neurology. 2010; 74:18-26.

33. Holick MF. Vitamin D deficiency. N Engl J Med. 2007;357:266-81. 